\title{
Effect of Feeding Admixture of Leaves of Different Mulberry Varieties on Growth Parameters and Economic Traits of Silkworm Bombyx Mori L.
}

\author{
${ }^{1}$ Kalshetti M. M., ${ }^{2}$ Latpate C. B., ${ }^{3}$ Dhandge S.R. \\ ${ }^{1}$ M. Sc (Agri.) Student, ${ }^{2}$ Assistant Professor, ${ }^{3}$ M. Sc (Agri.) Student, Department of Agril. Entomology College of \\ Agriculture, Latur, Vasantrao Naik Marathwada Krishi Vidyapeeth, Parbhani. (MS) India-413512
}

\begin{abstract}
Sericulture is an agro-based rural industry combining the features of agriculture and village industry. India is the only country in the world producing all the four types of natural textile silks from silkworms viz., Mulberry silkworm (Bombyx mori L.), Tasar silkworm (Antheraea mylitta D.), Muga silkworm (Antheraea assamensis) and Eri silkworm (Philosamia ricini). Of the four species, the mulberry silkworm is reared on large scale. Disease free eggs of silkworm bivoltine hybrid CSR4 x CSR2 were utilized. The treatments were leaves of $M-5(100 \%), \quad V-1(100 \%), \quad S-1635(100 \%), \quad M-5+V-1(60 \%+40 \%), \quad S-1635+V-$ $1(60 \%+40 \%), M-5+S-1635(60 \%+40 \%), V-1+M-5(50 \%+50 \%), M-5+V-1+S-1635$ (in equal proportion). The observations $\quad$ were recorded on the different economic traits of silkworm B. mori L. All the growth parameters of silkworm were found to be superior in the case of those larvae which were reared on 100\% leaves of V-1, compared to $100 \%$ leaves of M-5 (control treatment). Quality of good cocoon production mainly depends on mulberry garden management. It is vital part of successful silkworm rearing .However, majority of mulberry gardens are admixture of two to more varieties in Marathawada region. The observations were recorded on the different economic traits of silkworm Bombyx mori L. All the economic traits of silkworm were found to be superior in the case of those larvae which were reared on $100 \%$ leaves of V-1, as compare to among all.
\end{abstract}

Keywords: Sericulture, silkworms, cocoon, admixture, economic traits.

\section{Introduction}

In nature, insects produce or collect different products like silk, honey, bee wax, shellac, paints, medicine etc. Among these, silk production is gaining importance. Sericulture is an agro-based rural industry combining the features of agriculture and village industry. Today despite of man-made fibre, natural silk is durable and valuable. By producing self employment in rural areas, not only the rural migration is arrested but also the cottage and small industries get established in rural India. One hectare of land under mulberry in terms of productivity yields Rs. 80,000 worth of silk, which is quite attractive, compared to the other commercial crops. Mulberry leaf form the basic food material for silkworm (Bombyx mori L.) and bulk of goods produced in the world are from mulberry silkworm. Nearly 70 per cent of silk proteins produced by silkworm are directly derived from proteins of mulberry leaves. Mulberry leaf quality plays a predominant role in healthy growth of silkworm, Bombyx mori L. It is of primary importance as the cocoon production is directly influenced by the nutritive status of mulberry leaves and such cost of leaf production occurs for nearly 60 per cent of total cost of cocoon production.

\section{Materials And Methods}

The experiment was conducted in rearing house at Department of Agricultural Entomology, College of Agriculture, Latur in randomized block design with eight treatments replicated three times in order to study the growth and study of CSR4 x CSR2 bivoltine silkworm hybrid when fed on admixture of leaves mulberry during December 2011 to January 2012. Each replication consisted of randomly selected 100 worms in each treatment.

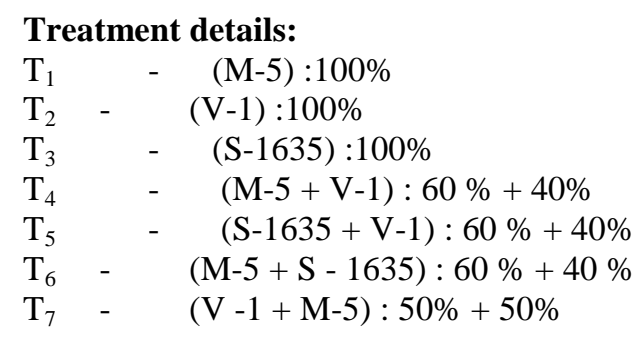


$\mathrm{T}_{8} \quad-\quad(\mathrm{M}-5+\mathrm{V}-1+\mathrm{S}-1635)$ equal proportion.

Treatments $T_{1}, T_{2}$ and $T_{3}$ comprise of sole leaf feeding of mulberry varieties viz., M-5,V-1 and S-1635, respectively among which M-5 mulberry variety was standard check. The treatment number 4 to 6 had the mixture of $60: 40$ per cent of leaves of M-5 + V-1, S-1635+V-1 and M-5 + S-1653. The seventh treatment was the mixture of equal quantity of leaves of V-1 and M-5 varieties. The eighth treatment was equal quantity of leaves of three mulberry varieties.

\section{Growth parameters:}

1. Larval weight (g)

The maximum larval weight was recorded by taking the weight of 10 matured larvae just before the onset of spinning, which was expressed in grams.

\section{Larval duration (Days)}

The total larval period in days was calculated by recording period from the date of hatching to the onset of spinning.

\section{Disease incidence (\%)}

The total number of healthy larvae and the larvae infected due to grasserie and flacherie diseases were recorded during the course of rearing in selected hybrids and the per cent incidence of the diseases was worked out as under and it was expressed in percentage.

$$
\text { Disease incidence }(\%)=\frac{\text { Number of diseased larvae }}{\text { Total number of larvae }}
$$

\section{Economic Traits:}

\section{Single cocoon weight $(\mathrm{g})$}

The cocoon weight was recorded on $6^{\text {th }}$ day of spinning, when the cocoon weights were assumed to be maximum. The average of 10 cocoons was taken as single cocoon weight and was expressed in grams.

\section{Yield of cocoon / 10,000 larvae brushed $(\mathrm{kg})$ :} computed.

Randomly selected 100 cocoons were weighed and the cocoon yield per 10,000 larvae brushed was

\section{Cocoon filament length $(\mathrm{m})$.}

Cocoon filament length was measured in meters by reeling 10 cocoons after boiling in the water with the help of epprovate.

\section{Larval weight (g).}

\section{Results And Discussion}

The data presented in Fig.1 illustrated that the larval weight of 10 matured larvae of mulberry silkworm varied in the range of 36.06 to $39.08 \mathrm{~g}$. significantly highest larval weight to the extent of $39.08 \mathrm{~g}$ was recorded due to feeding on the leaves of $\mathrm{T}_{2}$ i.e. $\mathrm{V}-1$. followed by $\mathrm{T}_{5}$ i.e. food containing 60 per cent leaves of S-1635 and 40 per cent leaves of V-1 (38.13 g) by weight. Significantly lowest larval weight was recorded in $\mathrm{T}_{4}(36.06 \mathrm{~g})$ i.e. the larvae fed on the leaves of M-5 (60\%) + V-1 (40\%) and was at par with $\mathrm{T}_{1}$ and $\mathrm{T}_{6}$. Patil (2004) and Gawade (2006) reported the larval weight of mulberry silkworm to the tune of 34.80 and 40.78 g respectively when grown on the leaves of mulberry variety, $\mathrm{V}-1$. These findings are in agreement with Patil (2004) and Gawade (2006). 


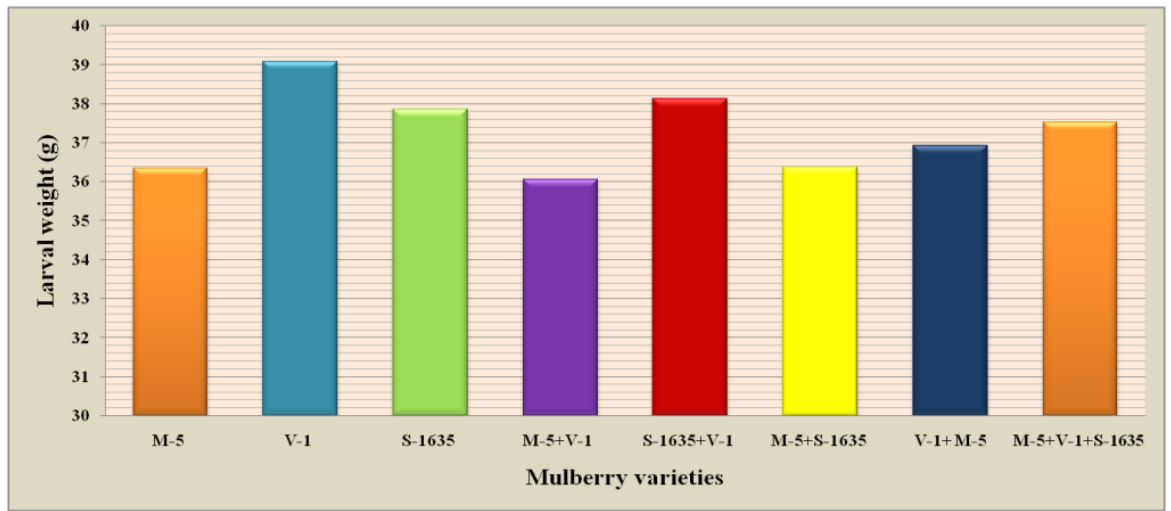

Fig. 1: Effect of feeding admixture of leaves of different mulberry varieties on weight of 10 mature larvae of silkworm (Bombyx mori L.).

\section{Larval duration (days).}

The data on the larval duration of silkworm, Bombyx mori L. are presented in Fig.2. Larval duration was observed in the range of 24.23 to 27.33 days. The $\mathrm{T}_{2}$ i.e. variety, V-1 (24.23 days) recorded significantly shorter larval duration over rest of the treatments except $\mathrm{T}_{3}$, i.e. S-1635 (24.40 days) and was followed by $\mathrm{T}_{5}$ i.e. mixed leaves of S-1635 (60\%) +V-1 (40\%) (25.10 days). Significantly longer larval duration over rest of treatments was recorded in larvae fed on leaves of M-5 (control) (27.33 days). Over rest of the treatments. Patil (2004) and Gawade (2006) reported the larval duration of mulberry silkworm to the tune of 22.36 and 22.23 days, respectively was recorded when grown on the leaves of mulberry variety, V-1. These findings are in agreement with Patil (2004) and Gawade (2006).

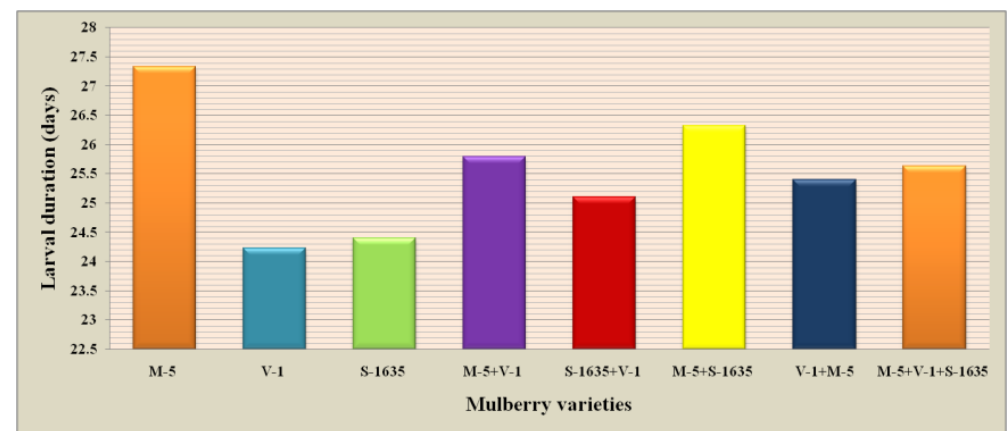

Fig. 2: Effect of feeding admixture of leaves of different mulberry varieties on total larval period of silkworm (Bombyx mori L.).

\section{Incidence of silkworm diseases (\%)}

The data on incidence of silkworm diseases are presented in Fig.3 The incidence of diseases was observed in the range of 2.86 to 5.00 per cent. Significantly lowest incidence of diseases was observed in the $T_{2}$ i.e. larvae fed on leaves of V-1 (2.86\%) over rest of the treatments tested except $\mathrm{T}_{3}$ i.e. S -1635 (3.00 $\%)$. Significantly highest incidence of diseases except $\mathrm{T}_{6}$ and $\mathrm{T}_{8}$ was observed in $\mathrm{T}_{1}$ i.e. larvae fed on leaves of M-5(control) $(5.00 \%)$.

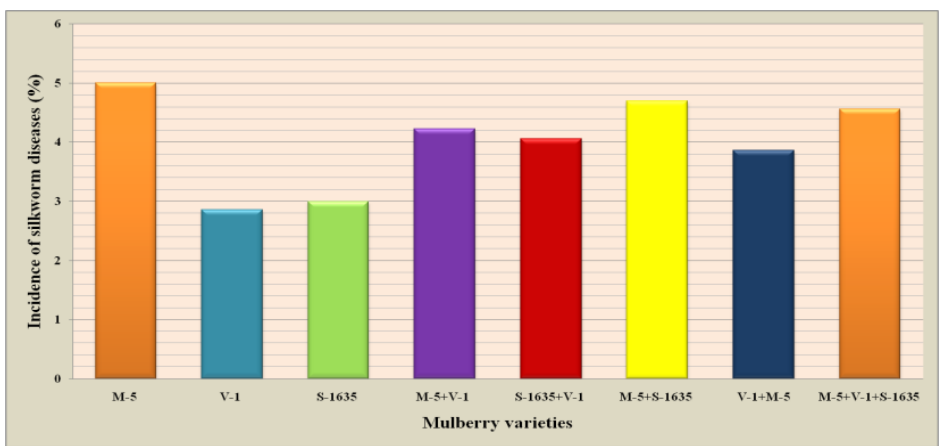

Fig. 3: Effect of feeding admixture of leaves of different mulberry varieties on the incidence of silkworm (Bombyx mori L.) diseases. 


\section{Single cocoon weight $(\mathrm{g})$.}

Data on single cocoon weights are presented in Fig.4.Results revealed that the single cocoon weight of silkworm, Bombyx mori L. varied from 1.32 to $1.58 \mathrm{~g}$. The significantly highest single cocoon weight of silkworm was observed when fed on 100 per cent leaves of variety V-1 (T2) (1.58 g) over rest of the treatments except T4 i.e. mixed leaves of M-5 (60\%)+ V-1(40\%) $(1.57 \mathrm{~g})$. The lowest single cocoon weight was recorded in T1 i.e. larvae fed on 100 per cent leaves of M-5 (control) (1.32 g) variety of mulberry.

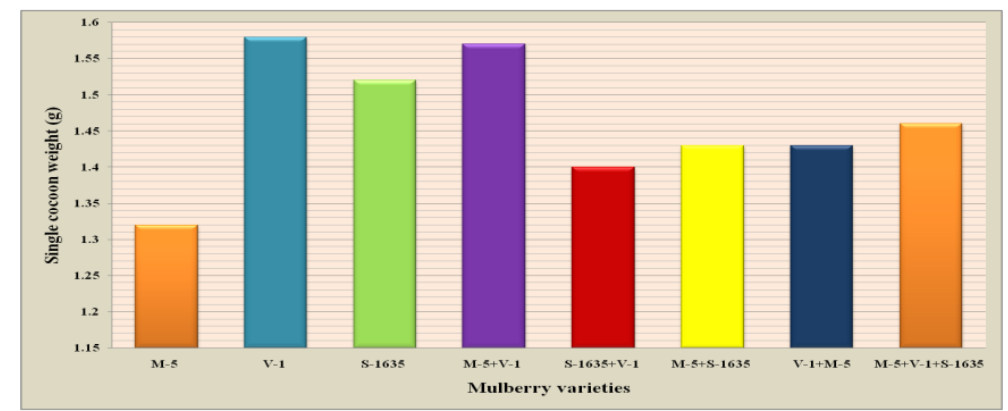

Fig. 4: Effect of feeding admixture of leaves of different mulberry varieties on the single cocoon weight of silkworm (Bombyx mori L.) (g).

Anonymous (2001) recorded single cocoon weight to the tune of $1.065 \mathrm{~g}$ when its larval stages were fed on the leaves of variety, V-1. Patil (2004) and Gawade (2006) recorded single cocoon weight of mulberry silkworm to the tune of 2.22 and $2.12 \mathrm{~g}$, respectively when grown on the leaves of variety, $\mathrm{V}-1$. The present findings are more or less in good agreement with the findings of Anonymous (2001), Patil (2004) and Gawade (2006).

\section{Cocoon yield per 10,000 larvae brushed (kg).}

The data presented in Fig.5 showed that the cocoon yield varied in the range of 13.13 to $15.63 \mathrm{~kg}$. when grown on leaves of different mulberry varieties Significantly the highest cocoon yield over rest of treatments was obtained when the larvae fed on 100 per cent leaves of mulberry variety, V-1(15.63 kg.) over rest of the treatment it was followed by T4 i.e. mixed leaves of M-5 (60\%)+ V-1 (40\%) (15.23 kg) and T3 i.e. larvae fed on 100 per cent leaves of S-1635 (15.00 kg). Significantly lowest cocoon yield was obtained by T1 i.e. larvae fed on leaves of M-5 (control) $(13.13 \mathrm{~kg}$ ). Rayar (2010) recorded the cocoon yield of bivoltine hybrid ranges between 13.76 and $14.55 \mathrm{~kg}$ when its larval stage fed on leaves of variety $\mathrm{V}-1$.

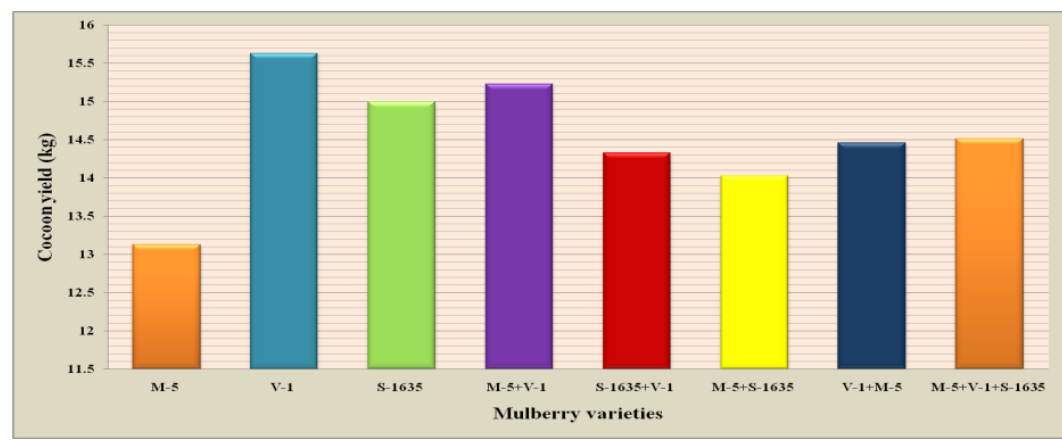

Fig. 5: Effect of feeding admixture of leaves of different mulberry varieties on the cocoon yield per 10,000 larvae brushed of silkworm (Bombyx mori L.)

\section{Cocoon filament length of silkworm $(\mathrm{m})$.}

The data on cocoon filament length of silkworm, Bombyx mori L. are presented in Fig. 6. The results revealed that cocoon filament length varied from 863 to $973 \mathrm{~m}$. The significantly highest filament length to the extent of $973 \mathrm{~m}$ was recorded by the larvae which were reared on 100 per cent leaves of variety V-1 of mulberry over rest of the treatments. It was followed by M-5 i.e. T1 $(943 \mathrm{~m})$ and T6 $(936 \mathrm{~m})$. However they were at par with each other. Whereas, significantly shortest cocoon filament length over rest of the treatment was recorded in T3 i.e. larvae fed on leaves of S-1635 $(863 \mathrm{~m})$. Jaydeb et al. (2002) reported the filament length in bivoltine hybrid was recorded from $849 \mathrm{~m}$ to $906 \mathrm{~m}$ during winter. Rayar (2010) also reported the cocoon filament length of mulberry silkworm to the extent of 943 to $1073 \mathrm{~m}$ when its larval stage reared on leaves of mulberry variety $\mathrm{V}-1$. 


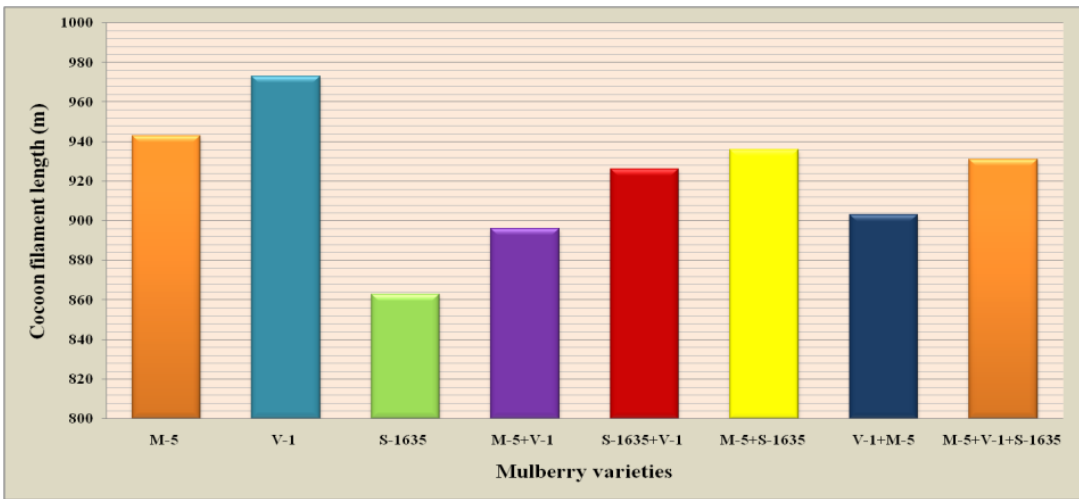

Fig. 6: Effect of feeding admixture of leaves of different mulberry varieties on the cocoon filament length of silkworm (Bombyx mori L.) (m).

\section{References}

[1]. Anonymous, (2001). Evaluation of mulberry varieties for rearing performance and economic traits of silkworm, (Bombyx mori L.) Annual report, Sericulture Research Unit, Marathwada Krishi Vidyapeeth, Parbhani. PP : 8-10.

[2]. Gawade, B.V. 2006. Evaluation of mulberry varieties for rearing performance and their different economic traits on silkworm (Bombyx mori L.) M.sc. (Agri.) Thesis, Marathwada, Krishi Vidyapeeth, Parbhani.

[3]. Jaydeb Ghosh; Senapati, S.K. and Baral, K. (2000). Performance of silkworm breeds with reference to disease occurrence during different seasons under terai ecological conditions of West Bengal. Ind. J. Agric.Sci.70 (4):234-238.

[4]. Kamate, G.S. Lande, U.L. and Mupade, R.V., 2010. Effect of different mulberry varieties on rearing of silkworm Bombyx mori L. in Maharashtra. International J. Plant Protection, 3 (2) : 210-212

[5]. Patil, S. N.(2004). Evaluation of mulberry varieties for rearing performance and their different economic traits on silk worm (Bombyx mori L). M.Sc. (Agri.) Thesis, Marathawada Krishi Vidyapeeth, Parbhani.

[6]. Rayar S.G. (2010). Evaluation of bivoltine silkworm hybrids suitable to nontraditional sericulture region of Karnataka. Karnataka J. Agric. Sci.,23 (5) : (798-799). 